CASE REPORT

\title{
Clinical and biological phenotype of a patient with familial glucocorticoid deficiency type 2 caused by a mutation of melanocortin 2 receptor accessory protein
}

\author{
H Rumié, L A Metherell ${ }^{1}$, A J L Clark ${ }^{1}$, V Beauloye ${ }^{2}$ and M Maes ${ }^{2}$ \\ Departamento de Pediatría, Escuela de Medicina, Pontificia Universidad Católica de Chile, Santiago, Chile, ${ }^{1}$ William Harvey Research Institute, Centre for \\ Endocrinology, Barts and the London, Queen Mary, University of London, London, UK and ${ }^{2}$ Division of Pediatric Endocrinology, Cliniques Universitaires St \\ Luc, UCL, 10, Avenue Hippocrate, 1200 Brussels, Belgium \\ (Correspondence should be addressed to M Maes; Email: maes@pedi.ucl.ac.be)
}

\begin{abstract}
Familial glucocorticoid deficiency (FGD) is a rare inherited disorder which may be caused by mutations in the ACTH receptor (melanocortin 2 receptor, MC2R) named FGD type 1 or by mutations in the MC2R accessory protein (MRAP) named FGD type 2. We report the case history of a male patient from birth until adulthood with FGD type 2, confirmed by a mutation of the MRAP gene.
\end{abstract}

European Journal of Endocrinology 157 539-542

\section{Introduction}

Familial glucocorticoid deficiency (FGD, OMIM 202200) is a rare autosomal recessive disorder which comprises two types: type 1 (FGD type 1) caused by mutations in the adrenocorticotropin (ACTH) receptor (melanocortin 2 receptor, MC2R; OMIM 607397) (1-3); and type 2 (FGD type 2) produced by mutations of MC2R accessory protein (MRAP; OMIM 609196) (4) In addition, in some patients no mutations were demonstrated for MCR2 or MRAP (5). Experimental evidence suggests that MRAP, previously identified as a protein expressed in differentiating adipocytes (6), is essential for MC2R expression and is critical in either the processing, trafficking, and/or function of MC2R (4). In the human, this protein is expressed in the adrenal cortex, pituitary, brain, testis, ovary, breast, thyroid, lymph node, skin, and fat (4), whereas MC2R is expressed in the adrenal cortex, the pituitary, skin, and fat tissue (7).

FGD is a potentially lethal disorder if not treated promptly. The clinical manifestations are due to glucocorticoid deficiency and are characterized by hypoglycemia (particularly in the neonatal period), jaundice, failure to thrive, hyperpigmentation of the skin, eczema, and increased susceptibility to infection (8). Low levels of plasma cortisol unresponsive to ACTH as well as high plasma ACTH and undetectable adrenal androgens are usually observed in the absence of mineralocorticoid deficiency (3). Glucocorticoid replacement is the recommended treatment. In the present case, we describe for the first time the clinical and biological phenotypes from birth until young adulthood of a patient with FGD type 2 .

\section{Case history}

The male patient was born at 39.5 weeks of gestation, to consanguineous parents of Caucasian origin, with a weight of $4.1 \mathrm{~kg}$, a length of $49 \mathrm{~cm}$, and a head circumference of $38 \mathrm{~cm}$. Pregnancy was uncomplicated and APGAR score was 10 at 5 min of life. At 9 h of life, he presented an episode of hypoglycemia (dextrostix 0), apnea, and bradycardia. He was treated with i.v. glucose and was transferred 5 days later to the pediatric intensive care unit (PICU) for suspicion of congenital cardiopathy. Upon admission to PICU, his blood sugar was $34 \mathrm{mg} / \mathrm{dl}$. During his stay in PICU, he acquired Klebsiella sepsis that responded successfully to antibiotic therapy and developed severe jaundice that required blood exchange transfusion. At 25 days of life, he was discharged from PICU with hypotonia thought to be due to kernicterus. At 1 month of life, he was again admitted for hypotonia and anemia. After a blood transfusion, he presented with seizures and bradycardia and was then transferred to our hospital for further investigation and management. No etiology of the seizures was found at that time: electroencephalogram, cerebral ultrasound and computed tomography, lumbar puncture as well as visual and auditory evoked potentials were normal. In particular, no electrolyte imbalance or hypoglycemia was identified. However, at day 15 of hospitalization, hypoglycemia $(13 \mathrm{mg} / \mathrm{dl})$ occurred again with hypotonia and 
hypothermia. During a hypoglycemic challenge test induced by fasting, blood glucose dropped to $23 \mathrm{mg} / \mathrm{dl}$ after $3 \mathrm{~h}$ with concomitant unmeasurable plasma cortisol ( $<28 \mathrm{nM}$, normal range $260-540 \mathrm{nM}$ ). An i.v. ACTH challenge test $\left(500 \mu \mathrm{g} / \mathrm{m}^{2}\right)$ showed no rise in cortisol after $4 \mathrm{~h}$ supporting the diagnosis of ACTH resistance. Plasma renin activity was normal $(4 \mathrm{ng} / \mathrm{ml}$ per $\mathrm{h}, \mathrm{N}$ : $\leq 5)$. In addition, ACTH insensitivity was confirmed by very high morning plasma ACTH concentrations $(>730 \mathrm{pg} / \mathrm{ml}$, $N$ : 10-50). Karyotype was 46,XY. The above-mentioned results lead to the presumed diagnosis of an isolated glucocorticoid deficiency secondary to ACTH insensitivity or FGD. Therefore, he was treated with hydrocortisone $\left(25 \mathrm{mg} / \mathrm{m}^{2}\right.$ per day). Additional investigations revealed the absence of adrenal autoantibodies, normal levels of very long-chain fatty acids, excluding respectively autoimmune adrenal disease and adrenoleukodystrophy. The presence of tears and the absence of achalasia and neuropathy made triple A or Allgrove syndrome very unlikely.

Clinical follow-up of the patient was remarkable for a steady height growth (close to 1 s.D.) leading to a final height of 0.5 S.D. $(178.0 \mathrm{~cm})$, within his sex-corrected target height range $(171.8 \pm 10 \mathrm{~cm}$; Fig. 1). Until 4 years, his weight remained at the upper limit $(21.6 \mathrm{~kg}$, +2.3 s.D.; body mass index (BMI) $19.9 \mathrm{~kg} / \mathrm{m}^{2},+2.8$ s.D.). Thereafter, weight and BMI increased steadily reaching at adulthood $102.8 \mathrm{~kg}\left(+2.8\right.$ S.D.) and $33.7 \mathrm{~kg} / \mathrm{m}^{2}$ $(+2.8$ s.D.). Skin hyperpigmentation and eczema were present since early infancy. Puberty onset (Tanner G2) was first documented at 10 years of age, with onset of pubarche at 11.9 years and axillary hair at 13.5 years, while near-adult pubertal status (A3P4G4) was achieved at 13.9 years of age. Bone ages, estimated by one of us (MM) from the Greulich and Pyle atlas, were retarded until chronological age 11.6 years (delayed from 3 to 1.5 years). At 12.5 years, his bone age was only delayed by 6 months.

Despite the physiologic supplementation of hydrocortisone, measured plasma ACTH levels were elevated, while plasma levels of androstenedione and DHEA-S remained low (1.3 nM (N: 2.5-7.5) and $1 \mu \mathrm{M}(\mathrm{N}: 2.5-12)$ respectively) at 21 years of age. Plasma testosterone was $13.9 \mathrm{nM}(\mathrm{N}: 13-35)$ with FSH: $1.8 \mathrm{mUI} / \mathrm{l}(\mathrm{N}: 1.4-9.9)$ and LH: $2.9 \mathrm{mIU} / \mathrm{l}$ ( $\mathrm{N}: 1.7-12.1$ ).Thyroid function tests were also normal (free thyroxine: $1.3 \mathrm{ng} \%$ and thyrotropin: $1.98 \mu \mathrm{U} / \mathrm{ml}$ ).

DNA sequencing had originally shown this patient to have a normal MC2R sequence. However, recent genetic testing identified a frameshift mutation (deletion of one of the three $\mathrm{G}$ residues between $128-130 \mathrm{bp}$ 130delG) causing a premature termination (V44X) in exon 4 of the MRAP gene (Fig. 2) (4), responsible for his isolated glucocorticoid and adrenal androgen deficiency. His parents were heterozygotes for the same mutation, as were two of his three sisters. The weights and BMI of the heterozygotes were $80.0 \mathrm{~kg}$ and $26.9 \mathrm{~kg} / \mathrm{m}^{2}$ respectively for the father, $104.5 \mathrm{~kg}$ and $41.6 \mathrm{~kg} / \mathrm{m}^{2}$ for the mother, $111.8 \mathrm{~kg}$,
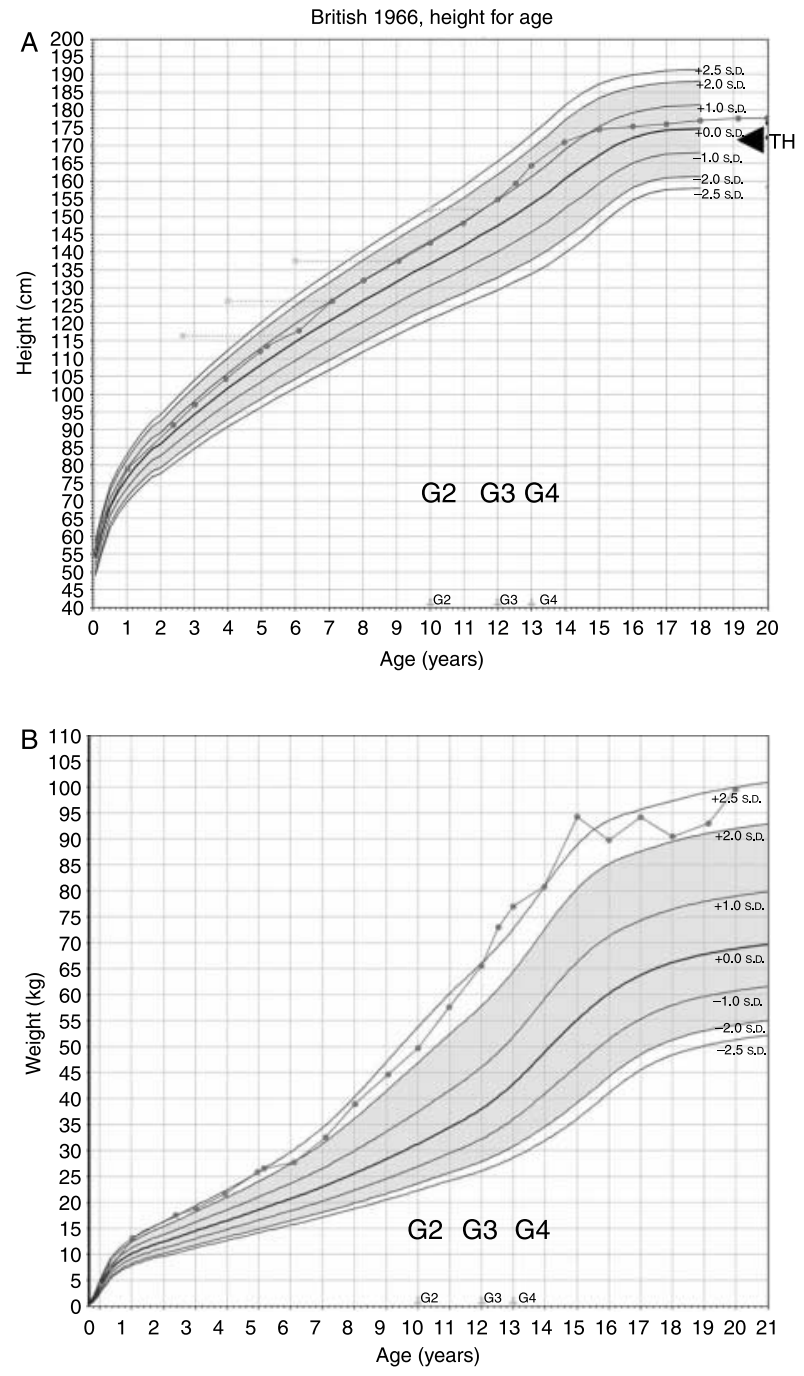

Figure 1 Growth curves for height (A) and weight (B). Squares represent the bone ages estimated by the Greulich and Pyle method. G indicates Tanner stages of genitalia. TH, sex-corrected target height.

$39.2 \mathrm{~kg} / \mathrm{m}^{2}$ for one of the sister and for the other sister $102.0 \mathrm{~kg}$ and $34.4 \mathrm{~kg} / \mathrm{m}^{2}$, while the only non-affected sister had a BMI of $24.4 \mathrm{~kg} / \mathrm{m}^{2}$ and a weight of $70.5 \mathrm{~kg}$.

\section{Discussion}

ACTH insensitivity syndromes are a group of rare diseases that may be lethal if not recognized. We report a case of FGD type 2 that presented during the neonatal period with hypoglycemia and jaundice and laboratory findings characteristic of an ACTH insensitivity syndrome: elevated plasma ACTH in the presence of unmeasurable plasma cortisol levels in the presence of a preserved reninaldosterone axis. A homozygous frameshift mutation leading to a premature termination in exon 4 of the MRAP gene (V44X) and hence a truncated protein was found in 

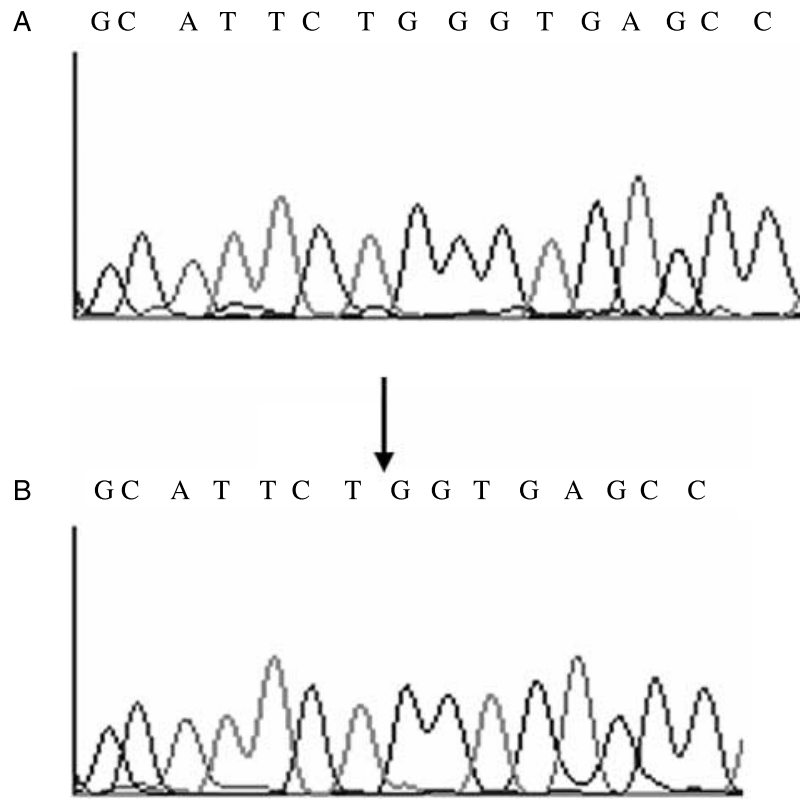

Figure 2 Partial sequence of exon 4 showing the 130 delG mutant. (A) wild-type and (B) mutant sequences. The position of the deleted $G$ is indicated by an arrow, this results in a frameshift and introduction of a premature stop codon (V44X).

our patient. To date, this is the only mutation reported in exon 4 of this gene - all other mutations affect exon 3. In accordance with the autosomal recessive mode of inheritance, his two sisters and the parents were heterozygous for this mutation.

Very recently, the case history of a 19-month-old Ethiopian male infant with a novel mutation of MRAP has been reported (9). The infant presented with severe psychomotor retardation, spastic quadriparesis, and microcephaly due to severe symptomatic and recurrent hypoglycemia. The authors speculated that this particular severe phenotype could be due to this novel MRAP mutation. Since our patient had normal psychomotor development despite episodes of neonatal hypoglycemia, we believe that the neurological sequelae of this young infant with FGD are more likely due to the delayed diagnosis and treatment of the hypoglycemia, rather than the nature of the MRAP mutation.

Frequent minor infections or a single major infectious episode are additional modes of presentation of FGD as in our patient, who presented with sepsis during the neonatal period. Excessive pigmentation of the skin is often seen in these patients and was present in our patient since early infancy.

While patients with FGD type 1 and 2 share many common clinical features, Clark and Weber reported that patients with the ACTH receptor mutations have a mean height that is about 2 s.D.s greater than normal, whereas patients with FGD type 2 have heights that fall within the normal distribution (3). In line with these findings is the adult height of our patient, which was appropriate for his target. In contrast to the advanced bone ages reported in some patients with FGD type 1 $(10,11)$, the bone ages of our patient were always retarded until 12.5 years of age, 2.5 years after onset of gonadarche. Whether the difference in skeletal maturation between the two types of FGD is real or spurious will require further observations.

ACTH is required for normal adrenal androgen secretion, which triggers adrenarche at around 7 years of age. Patients with FGD have no adrenarche and often have undetectable levels of adrenal androgens as measured in our patient, in whom androstenedione and DHEA-S were very low even at an adult age. These findings underline the importance of ACTH, MC2R, and MRAP in stimulating secretions of androgens by the adrenals. Although he did not develop adrenarche, his gonadarche occurred at a normal age. Despite the lack of expression of MRAP in the testis, puberty occurred at a normal age and progressed normally in our patient.

His ACTH remained elevated despite physiological cortisol substitution. This incomplete ACTH suppression may be explained by the ineffective MC2R-dependent short feedback loop of ACTH on the pituitary or the hypothalamus (10).

It is well known that the hypothalamic melanocortin system in humans plays an important role in energy balance (11). $\alpha$-melanocyte-stimulating hormone, a pro-opiomelanocortin (POMC) cleavage product, is an anorectic peptide acting as an agonist of MC4R in the hypothalamic arcuate nucleus leading to an increase in energy expenditure and a decrease in food intake. Patients with defects in the synthesis and processing of POMC or mutations of the MC4R gene have early onset obesity. Whether the MRAP mutation described in our patient played a role in his obesity is, at this point, purely speculative. Indeed, MRAP is expressed in the pituitary and the brain and might be essential for the proper functioning of the hypothalamic melanocortin system (12). By analogy with patients with gene mutations who develop severe obesity in early infancy, it is tempting to hypothesize that the MRAP mutation observed in our patient could be responsible for his obesity if MRAP were essential for the expression and activation of other melanocortin receptors. Only scientific evidence and clinical observation will clarify this hypothesis.

In summary, we describe for the first time the longterm clinical and biological follow-up of a young male patient affected with FGD type 2 due to a rare mutation of MRAP. While some clinical and hormonal features are shared with FGD type 1, others such as height and skeletal maturation may be different.

\section{References}

1 Clark AJ, McLoughlin L \& Grossman A. Familial glucocorticoid deficiency associated with point mutation in the adrenocorticotropin receptor. Lancet $1993 \mathbf{3 4 1} 461-462$. 
2 Tsigos C, Arai K, Hung W \& Chrousos GP. Hereditary isolated glucocorticoid deficiency is associated with abnormalities of the adrenocorticotropin receptor gene. Journal of Clinical Investigation $1993922458-2461$.

3 Clark AJ \& Weber A. Adrenocorticotropin insensitivity syndromes. Endocrine Reviews $199819828-843$.

4 Metherell LA, Chapple JP, Cooray S, David A, Becker C, Ruschendorf F, Naville D, Begeot M, Khoo B, Nurnberg P, Huebner A, Cheetham ME \& Clark AJ. Mutations in MRAP, encoding a new interacting partner of the ACTH receptor, cause familial glucocorticoid deficiency type 2. Nature Genetics 200537 166-170.

5 Weber A \& Clark AJ. Mutations of the ACTH receptor gene are only one cause of familial glucocorticoid deficiency. Human Molecular Genetics 19943 585-588.

$6 \mathrm{Xu} \mathrm{A,} \mathrm{Choi} \mathrm{KL,} \mathrm{Wang} \mathrm{Y,} \mathrm{Permana} \mathrm{PA,} \mathrm{Xu} \mathrm{LY,} \mathrm{Bogardus} \mathrm{C} \mathrm{\&}$ Cooper GJ. Identification of novel putative membrane proteins selectively expressed during adipose conversion of 3T3-L1 cells. Biochemical and Biophysical Research Communications 2002293 1161-1167.

7 Blondet A, Doghman M, Durand P, Begeot M \& Naville D. An E-box-containing region is involved in the tissue-specific expression of the human MC2R gene. Journal of Molecular Endocrinology 200432 811-823.
8 Perry R, Kecha O, Paquette J, Huot C, Van Vliet G \& Deal C. Primary adrenal insufficiency in children: twenty years experience at the Sainte-Justine Hospital, Montreal. Journal of Clinical Endocrinology and Metabolism 200590 3243-3250.

9 Modan-Moses D, Ben Zeev B, Hoffmann C, Falik-Zaccai TC, Bental YA, Pinhas-Hamiel O \& Anikster Y. Unusual presentation of familial glucocorticoid deficiency (FGD) with a novel mrap mutation. Journal of Clinical Endocrinology 200691 3713-3717.

10 Boscaro M, Sonino N, Paoletta A, Rampazzo A \& Mantero F. Evidence for ultra-short loop autoregulation of adrenocorticotropin secretion in man. Journal of Clinical Endocrinology and Metabolism 198866 255-257.

11 Peters A. The self-similarity of the melanocortin system. Endocrinology 2005146 529-531.

12 Pritchard LE, Turnbull AV \& White A. Pro-opiomelanocortin processing in the hypothalamus: impact on melanocortin signalling and obesity. Journal of Endocrinology $2002 \mathbf{1 7 2}$ 411-421.

Received 12 April 2007

Accepted 2 July 2007 